\title{
Chapter 21 \\ Initiatives to Promote School-Based \\ Mental Health Support by Department \\ of Educational Sciences, University \\ of Education Under Vietnam National \\ University
}

\author{
Hoang Phuong Hanh, Tran Thanh Nam, and Le Anh Vinh
}

\begin{abstract}
This chapter describes a case study of the university's attempts to support general education institutions through the COVID-19 pandemic crisis. Applying the School-Based Mental Health Collaboration, faculties from the University of Education, Vietnam National University Hanoi took a whole-school approach to promote mental health services for students all over the country via various channels. With multiple training webinars on studying and coping skills during social distancing periods for students, classroom consultation skills for teachers, initiatives from the university attracted remarkable responses from the community. Suggestions to improve the effectiveness and sustainability of the efforts, including digitalization consideration, targeting and effective mobilization of resources, dissemination of learning materials, and long-term planning, are discussed in the last half of the chapter, after reviewing and evaluating their impact and potential.
\end{abstract}

\subsection{Introduction}

The COVID-19 pandemic has induced a wide range of significant socioeconomic concerns all over the globe, including in the education sector. In Vietnam, containment efforts led by the Government, including a three-month period of school closures, have led to multiple immediate responses intended to sustain educational

H. P. Hanh · L. A. Vinh $(\bowtie)$

Vietnam Institute of Educational Sciences, Hanoi, Vietnam

e-mail: hanhhp@vnies.edu.vn; Vinhla@vnies.edu.vn

T. T. Nam

University of Education, Vietnam National University Hanoi, Hanoi, Vietnam

e-mail: namtran@vnu.edu.vn 
continuity (La et al., 2020). While comprehensive actions were initiated by the Ministry of Education and Training (MOET) regarding the switch from conventional methods of education to online and TV learning using technological tools, which involved thousands of schoolteachers and managers across the country, little systematic attention was paid to address the mental and emotional needs of teachers and students (Vu et al., 2020). The disruptions in daily learning routines meant that many students were not able to engage consistently with the new forms of schooling provided by the temporary responses (Tran et al., 2020; Trung et al., 2020). Distance learning requires skills that might be novel to many students, such as independent study, time management, self-discipline, schoolwork, and social life balance. Those from vulnerable groups could face more challenges, leading to a higher risk of family abuse, dropping out of school to engage in child labor, or early marriage, as a result of prolonged school shutdowns and income constraints (Tran et al., 2020). For teachers, both professional and emotional support are much needed to help them overcome increased pressure from adapting to new teaching modes and demands in keeping students engaged remotely while at the same time, coping with the new pressures on their family income.

This gap in the existing action plans of education agencies and institutions highlighted the necessity of extensive efforts on a national scale to address mental health as well as social and emotional needs of students and teachers (Nguyen et al., 2013). This is particularly critical during the pandemic as well as in the long term since education in Vietnam has always been achievement-driven without sufficient focus on the socioemotional development of learners. As psychological counseling is a new concept in Vietnam, MOET has stipulated an official tenured position for this in every school; however, there is a serious lack of specialists based at schools due to a human resource deficit. Consequently, if issues were to arise, the existing arrangements are professionally subpar. Prior to the pandemic, the Department of Educational Sciences of the University of Education at Vietnam National University (VNU) has led attempts to assist K-12 schools, such as consulting for school leaders and teachers on mental support for students, organizing courses, seminars, workshops, TV shows, and digital dissemination of information to raise social awareness and enhance teachers' skills in counseling. However, the focus of these attempts was mainly limited to school bullying. There has been an increase in the number of reported incidents in educational settings recently, including child molestation, teen depression, and behavioral problems. In response, the measures undertaken by schools are often slow and not well-targeted. These problems have become more critical during school shutdowns and social distancing periods, increasing the need for timely interventions.

\subsection{Theory of Action}

The efforts generated here are based theoretically on The School-Based Mental Health Collaboration (SBMHC) model by Eppler-Wolff et al. (2019), which is grounded in attachment and mentalization theory and practice. The model 
highlights the significant role of teachers and teacher-child attachment, as compared to parent-child attachment, in shaping students' behaviors (Ainsworth, 1978; Holmes, 1993; Eppler-Wolff et al., 2019). Safe and trusting teacher-child relationships can help soothe the trauma originating from insecure parent-child attachments, particularly those impeding positive learning habits (Rass, 2017). SBMHC also takes the approach of the mentalization theory, which posits that if a caregiver or a therapist (or a teacher in this context) can take a mentalizing stance, he or she can understand his/her own mental states as well as those of others (Steele et al., 2015). From this, it is possible for them to modulate disruptive feelings of student patients.

This model was chosen because it describes a whole-school approach to mental health services, which involves all stakeholders, including students, teachers, parents, and school managers, each with their own perspective and role in mind. As the model focuses on classroom consultation, the clinical supervision of classroom consultants-who, in the case of Vietnam, are also the teachers-is particularly important. This is expected to be delivered by university clinicians. The clinical supervisors are supposed to be responsible for using mentalization practice to monitor and support the teacher consultants with their experiences with student patients (EpplerWolff et al., 2019).

\subsection{Profile of the University in Charge}

As the first modern university established, and one of the two national universities in Vietnam, VNU has undergone various stages of development since 1906. VNU is the largest comprehensive higher education and research center in Vietnam. Accommodating over 2300 academic staff from 34 member universities, schools, institutes, centers, and service units, and offering nearly 500-degree programs for about 45,000 undergraduate and graduate students, VNU is entrusted with the mission of producing highly qualified human resources and a talent pool for the industrialization and modernization of the country. VNU holds a special position in Vietnam's higher education system, operating according to a special regulation promulgated by the Prime Minister. VNU reports directly to the Prime Minister and has high autonomy in personnel organization, academic programs, scientific research and technological development, planning and finance, international relations, and other fields. VNU is authorized to work directly with ministries, ministerial-level organizations, governmental bodies, and people's committees of central cities and provinces on affairs related to VNU. VNU's universities, schools, and institutes maintain their juridical entity status as higher education and scientific research institutions regulated by the Law on Education and the Law on Science-Technology.

The initiative examined in this case study originated from the Department of Educational Sciences at the University of Education (UEd), a member school of VNU since 1999. UEd is responsible for training teachers, educational specialists, and managers for all academic levels in Vietnam and is also a research hub on 
pedagogical sciences, educational management, and psychological studies. UEd also serves as one of the consultancy units for MOET and local education agencies about strategic plans, policies, and program implementation for educational development, together with scientific research and technological services. The university offers undergraduate and graduate degree programs in Subject Specialized Pedagogy, Educational Management, Testing and Assessment, Developmental Clinal Psychology, and various other short-term training courses. Established in 2009, the Department of Educational Sciences is responsible for implementing training programs on educational sciences and leading scientific research in Economic Education, Social Education, Educational Statistics, School Psychological Counselling, Developmental Clinical Psychology, School Social Works, Therapeutic Education, and Lifelong Learning. In parallel with improving research quality standards in the field of Educational Sciences, the department also envisions supporting technology transfer and offering high quality services of psychological counseling for K-12 teachers and students. The department has been running various training courses in education and life skills, school counseling, and professional development for teachers and school leaders.

As a university specialized in teacher training and educational sciences, the University of Education (UEd) has realized that although lifelong learning is crucial for teachers, most of them only receive prescriptive on-the-job training on teaching pedagogies. Voluntary training, based on individual teacher needs, has been relatively rare and needs to be better promoted among teacher networks. Over the past few years, UEd has launched several new degree programs and many need-based teacher professional development courses and modules in order to familiarize schoolteachers with the idea of actively seeking learning opportunities in order to remain up-to-date on new skills and capabilities. This is aligned with the vision and mission of the university, which is to create educators for tomorrow who are globally competent, lifelong learners, and inspirers. The teaching approach of UEd is liberal and learner-centered, valuing the autonomy of teacher trainees. Therefore, much emphasis is placed on creating changes in the perceptions and attitudes of teachers about continuous learning and professional development.

A considerable proportion of research at VNU UEd Department of Educational Sciences is concerned with K-12 education. Hence, many of the activities and initiatives by the university are tied with general schools. UEd even founded an annex school called High School of Educational Sciences, which serves as a practical and educational research site for the university. This initiative to provide support for the mental health and socioemotional development of students and teachers was undertaken as part of the university's stated mission and operational approach to strengthen the role of university training and research on the enhancement of general education. These efforts, which were implemented through the voluntary and uncompensated work of university staff and faculty, also reflect the sense of social responsibility felt by the university to ease the consequences and aid those in need during the time of crisis resulting from the pandemic. The Board of Presidents at VNU also saw the opportunity to promote social awareness and understanding about the role of mental and socioemotional well-being in education, together with the popularity of the university in terms of its vision, mission, and function. 


\subsection{Implemented Efforts in Response to the Pandemic Crisis}

Given the emergency situation during the pandemic, UEd Department of Educational Sciences has collaborated with the Department of Student Affairs under MOET and partnered with UNICEF to initiate a series of rapid digitally-based responses, which aim to provide mental and socioemotional support for K-12 teachers and students. All academic faculty were involved on a voluntary basis, and there were little or no additional technical costs incurred. Overall, these efforts were implemented through three main forms: webinars, social network channels, TV shows, and printed/digital learning materials.

The first attempt implemented was a three-hour webinar on mental health for students at High School of Educational Sciences in March 2020. Students were given notice about the event with a register/login link on a first-come, first-serve basis. The topics discussed revolved around stress management, anxiety, teen depression, sleep deprivation, and attention deficiency when learning online at home. Explanations, advice, and guidance were provided by the guest speakers, who were also academic faculty of the Department, to help students develop emotional management and problem-solving skills for a healthy mental life. The event was limited to only 100 Zoom accounts at one time, but the real number of students in attendance was larger since many students gathered into groups to follow the session from one PC/laptop. However, there were still many more interested students who were unable to participate in the event, including those from other upper secondary high schools. As a result, the recording video of the session was shared on UEd's official website sot that all students interested could view it.

As the link to this first webinar was reposted many times on different social media platforms, it was noticed that this issue attracts not only students but also teachers, who have been struggling to find ways to support and engage their students in sustaining school work while leading a healthy social life. As mentioned above, schools in Vietnam do not have specialized psychological counselors for students, so it is important that teachers are equipped with sufficient knowledge and skills to support their learners. This has led to the second, larger-scale series of webinars targeting teachers and managers in Hai Phong and Thai Binh provinces in early April. The Department of Student Affairs under MOET contacted provincial Departments of Educational and Training to reach out to every elementary and secondary school in the region to nominate teaching staff to attend. Additionally, interested teachers and parents in need of guidance on how to support their children mentally could also self-register for the event. The webinar attracted over 18,000 participants from 130 Zoom accounts to discuss career orientation and school counseling tips and experiences, as well as the skills required of homeroom teachers to adhere to the new national curriculum framework with the competency development approach.

Participants at the webinars were guided through a step-by-step process of effective school counseling, focusing on skills such as identifying common emotional behaviors of students, understanding the underlying causes of their misbehaviors, 
and knowing how to assist those with socioemotional behavioral problems with active listening, reflective emotions, and empathy skills. The webinar series enabled teachers to further understand the psychological issues of students and become familiar with the five-step procedure to deliver mental support for students. Assessment tools for initial diagnosis of socioemotional and behavioral problems as well as different sources of high quality learning materials were also shared in the sessions.

After the series of webinars, there were many follow-up questions and an observed need for consistent sharing and discussion of these topics. As such, academic staff joined the Vietnam Students Forum (HSF) in an online counseling program called "Accompanying students through COVID-19" held on a Facebook fan page to deliver counseling support and help students improve their academic and life skills when learning at home. Every week, the group of specialists from UEd created counseling content in the form of video clips or infographics, which were then sent to the forum. The topics covered included improving motivation, digital safety and resilience, coping strategies for tiredness and anxiety, improving attention span for online learning, and maintaining positive social relationships. Each of these posts has received approximately five to ten thousand views and comments. A separate Facebook page was created and dedicated to improving digital safety and resilience, with the aim of enabling school students to become proficient digital citizens who can be active, thrive, and learn in the digital world while at the same time are able to protect themselves and others from potential risks.

In addition to online social media pages, academic faculty from UEd were invited to be guest speakers on a TV chat show program to discuss various social and educational issues. Each of the show's episodes was devoted to providing information using the speaker's expertise or counseling service about a controversial topic in education, such as helping children and adolescents control time spent on digital devices, handling cyberbullying, or choosing majors at the undergraduate level. Some, but not all, of the episodes targeted a parent audience and offered guidance for supporting children at home in independent learning skills and reentering school life after social distancing.

The TV show sessions and weekly infographic posts on the HSF fan Facebook page were so popular that the experts from UEd received even more questions and inquiries for additional detailed information. The Board of Presidents at VNU and Board of Rector at UEd decided to launch a specialist team, which included academic staff from the Department of Educational Sciences and the Department of Technological Education, to compile, consolidate, reorganize, and develop the ready-made infographics into comprehensive guidebooks. Within six weeks of early April, the team had successfully created three downloadable books on mental health care and career orientation for students and on the digital transformation in education for teachers. Information in these documents is presented in a user-friendly format with links or QR codes linking to online video clips and interactive questions and quizzes to engage readers. In addition to the download links on the UEd 
website, the printed versions of these guidebooks were distributed to 27 Provincial Departments of Education and Training in North Vietnam for introduction to regional school leaders and teachers.

\subsection{Monitoring and Reflections}

The effectiveness of these efforts to date can be assessed by the level of engagement from the community. The number of participants in every webinar session always exceeded expectations. In addition to the large number of views and comments on social media pages and follow-up questions sent to the experts, news articles and reports about the webinars and publications were also widespread on electronic news sites and TV. These efforts have been considered a successful stepping-stone to raising social awareness about mental health and essential life skills for students in order to help sustain education continuity during the pandemic. Mental health care is a relatively new concept to many Vietnamese people even though many students have struggled with difficulties and socioemotional and behavioral problems regularly prior to, but especially during, the pandemic. However, there is a serious lack of a support system for this vulnerable group. Given the available resources and how critical the situation is, dissemination of information and efforts to engage and offer guidance to improve awareness and attitudes are the key solutions to improve the situation.

These efforts have demonstrated that demand for school psychological counseling and support in the acquisition of life skills in general, and particularly during times of crisis, is huge, but has not been properly undertaken. Children and adolescents are exposed to various types of risks from their daily habits and the digital world but do not know how to seek help, while furthermore, the availability of specialists in the field falls immensely short. In addition, awareness and perception of schools and parents regarding this topic have not been sufficiently improved in order to address this need. It is, therefore, crucial to equip teachers and parents with scientific knowledge, skills, and tools for basic psychological support and intervention at school and at home. This is what went beyond expectations since, at the beginning, efforts were only to target K-12 teachers and students. Initially, there were no deliberate efforts to engage parents in the activities. However, feedback from teachers and students as well as the naturally growing interest from groups of parents have informed the team about the significant role of parents in collaborating with schools to help stimulate students. This was even more critical during social distancing as students spent the entire time at home with parents. Efforts by teachers could be ineffective without understanding and support from the parental side.

In terms of teachers, it has been noted that the demand for psychological counseling and mental support of this group is as high as students. Teachers would be unable to assist learners if they themselves also suffer from mental issues and are in need of help. As a result, in addition to training on innovative teaching methods and counseling skills, more self-help coping strategies and external support are needed 
for teachers. This also means that school leaders and local educational managers should have been involved more intensively and directly to develop school counseling skills to share the burden and better support teachers.

What remains especially difficult is developing a monitoring system to measure the sustainability of the effects of the interventions. Despite considerably high levels of interest and interaction with the webinars and guidebooks, there has been no examination of how things have actually transitioned into real life. Students and teachers have been encouraged to provide reflections and feedback through online minigames on social network pages, but the responses have not been widespread. Moreover, the growing interest and demand for learning and counseling from the community were larger than the available technical infrastructure and human resources could support. Since there was no funding for technical facilities, the available digital platforms for the webinars were unable to accommodate the full number of interested participants. The usability of the free tools for creating content and designing the guidebooks also impeded productivity under such a tight time frame. Additionally, even though the expert team worked beyond their expected responsibilities to serve the community, time constraints made them unable to offer help and support to every individual case reported through different channels.

As mentioned earlier in the SBMHC model, the role of clinical supervisors is key to the success of classroom consultancy. However, this was not possible at this beginning stage due to time, financial, technical, and personnel constraints. The involvement of school leaders and parents has also not been sufficient. The attempted efforts mainly revolved around teacher professional development and teacherstudent relationship at a surface level.

\subsection{Ways Forward}

Although these efforts were initiated in response to the emergency situation caused by the pandemic, reality has proven that this is not a one-off occasion as there is always chance for similar relapses. Preparation for sustainable solutions is a must; therefore, plans are being drafted from the experiences and lessons learned from the initial attempts.

First, digital pathways are ideal channels to approach children and adolescents in this day and age. When encountering problems, students might not confide with or accept support from parents or teachers but are much more willing to seek out information and advice from the Internet, particularly when youth nowadays have access to digital devices and develop good IT skills from a very early age. Since schools were reopened in the country in May 2020, three months after COVID-19 was announced to be a global pandemic, the Facebook page for digital safety and resilience continues to post constant updates with more detailed guidance on digital learning skills and self-management strategies. This is important even beyond the pandemic context because blended learning is becoming predominant in modern education. Together with more webinars, discussion threads, and forums on social network pages, online counseling services are also expected to be a promising and 
cost-effective support method given the current lack of facilities and human capital in charge.

Second, the development and production of learning materials need to be further reinforced. Printed and online publications are still one of the best ways to disseminate knowledge and improve community awareness, particularly considering the serious scarcity of official knowledge available in the Vietnamese language in this field. Product materials need to cover a wider range of topics and address the needs of students, teachers, and also parents. This is specifically important to teachers and parents who cannot attend and follow intensive training courses. There also needs to be more detailed communication and distribution plans for these products so that more diverse audiences are targeted. The consolidation, revision, and sharing of these products will be undertaken systematically to allow open access, to the exchange of ideas, and constantly update information.

Third, right after the pandemic and social distancing, the focus of support should be customized to better target students of vulnerable groups, such as those with economic constraints, domestic violence, or learning difficulties. These groups are considered in critical need of mental support and guidance. TV broadcasts and printed materials work more effectively with these groups since many of them cannot afford personal digital devices to access online-based sources. Home-based counseling for the whole family and extra support for parents are also necessary to help these children reengage with academic work or return to school. Many of these students have opted to drop out due to the psychological difficulties caused by the alternative online learning mode during school shutdowns in addition to economic issues.

Last, but most importantly, in order to realize all of the aforementioned plans in the coming period, there needs to be a specific road map and investment budget for human resources and network development. Staff from one academic department of VNU and MOET Department of Student Affairs were only the initiators who laid the first stepping-stone. The next step requires synchronized collaboration of all stakeholders from policymakers, educational authorities, school leaders, teachers, and the community. Teachers need long-term support to effectively deliver a socioemotional learning curriculum as a solid foundation for student control of their mental well-being (Eppler-Wolff et al., 2019). It is, therefore, important to spread this vision and involve more institutions and organizations of expertise in the field with a view to scale the efforts for extensive and sustainable effects.

\section{References}

Ainsworth, M. D. S. (1978). The Bowlby-Ainsworth attachment theory. Behavioral and Brain Sciences, 1(3), 436-438. Retrieved from https://www.cambridge.org/core/article/ bowlbyainsworth-attachment-theory/3915528486A6062F4DBEF0720406C462. https://doi. org/10.1017/S0140525X00075828.

Eppler-Wolff, N., Martin, A., \& Homayoonfar, S. (2019). The School-Based Mental Health Collaboration (SBMHC): A multi-level university-school partnership. Journal of Infant, Child, and Adolescent Psychotherapy, 18(1), 13-28. Retrieved from https://doi.org/10.1080/1528916 8.2019.1573095. 
Holmes, J. (1993). John Bowlby and attachment theory: Psychology Press.

La, V.-P., Pham, T.-H., Ho, M.-T., Nguyen, M.-H. P., Nguyen, K.-L., Vuong, T.-T., ... Vuong, Q.-H. (2020). Policy response, social media and science journalism for the sustainability of the public health system amid the Covid-19 outbreak: The Vietnam lessons. Sustainability, 12(7), 2931. Retrieved from https://www.mdpi.com/2071-1050/12/7/2931.

Nguyen, D. T., Dedding, C., Pham, T. T., Wright, P., \& Bunders, J. (2013). Depression, anxiety, and suicidal ideation among Vietnamese secondary school students and proposed solutions: A cross-sectional study. BMC Public Health, 13(1), 1195. Retrieved from https://doi.org/10.118 6/1471-2458-13-1195.

Rass, E. (2017). The Allan Schore reader: Setting the course of development: Routledge.

Steele, M., Murphy, A., \& Steele, H. (2015). The art and science of observation: Reflective functioning and therapeutic action. Journal of Infant, Child, and Adolescent Psychotherapy, 14(3), 216-231. Retrieved from https://doi.org/10.1080/15289168.2015.1070558.

Tran, T., Hoang, A.-D., Nguyen, Y.-C., Nguyen, L.-C., Ta, N.-T., Pham, Q.-H., ... Nguyen, T.-T. (2020). Toward sustainable learning during school suspension: Socioeconomic, occupational aspirations, and learning behavior of Vietnamese students during Covid-19. Sustainability, 12(10), 4195. Retrieved from https://www.mdpi.com/2071-1050/12/10/4195.

Trung, T., Hoang, A.-D., Nguyen, T. T., Dinh, V.-H., Nguyen, Y.-C., \& Pham, H.-H. (2020). Dataset of Vietnamese student's learning habits during Covid-19. Data in Brief, 30, 105682. Retrieved from http://www.sciencedirect.com/science/article/pii/S235234092030576X. https://doi. org/10.1016/j.dib.2020.105682.

Vu, C.-T., Hoang, A.-D., Than, V.-Q., Nguyen, M.-T., Dinh, V.-H., Le, Q.-A. T., ... Nguyen, Y.-C. (2020). Dataset of Vietnamese teachers' perspectives and perceived support during the Covid-19 pandemic. Data in Brief, 31, 105788. Retrieved from http://www.sciencedirect.com/ science/article/pii/S235234092030682X. https://doi.org/10.1016/j.dib.2020.105788.

Hoang Phuong Hanh is a MA linguistics graduate from the University of London, UK and currently working as a researcher at Vietnam Institute of Educational Sciences. She is also a $\mathrm{PhD}$ student in education at the University of Auckland, New Zealand. She has published works concerning STEM education, youth's digital capacity, and educational disparities. Her research interests also include educational leadership and policy as well as education innovations and reforms.

Tran Thanh Nam earned his PhD in clinical psychology from Vanderbilt University, USA and is now the Dean of Faculty of Educational Sciences at the University of Education, Vietnam National University Hanoi. He has over ten years of postgraduate teaching experience, focusing on psychopathology, psychometrics, and therapeutic intervention. His research includes adaptation and calibration of assessment tools for early detection, adaptation, and calibration of intervention programs for children and adolescents with developmental disorders, behavioral problems, anxiety, depression, post-trauma stress disorders.

Le Anh Vinh earned his Master in Education and PhD in Mathematics at Harvard University and is currently Vice Director General of Vietnam Institute of Educational Sciences (VNIES). He has had more than 70 international publications (both in Math and Education) and is leading a research group at VNIES on developing Vietnam Educational Strategy Framework 2021-2030. Professor Le Anh Vinh is currently the leader of many cross-national education projects on innovative teaching, STEM education, skills-based learning. 
Open Access This chapter is licensed under the terms of the Creative Commons Attribution 4.0 International License (http://creativecommons.org/licenses/by/4.0/), which permits use, sharing, adaptation, distribution and reproduction in any medium or format, as long as you give appropriate credit to the original author(s) and the source, provide a link to the Creative Commons license and indicate if changes were made.

The images or other third party material in this chapter are included in the chapter's Creative Commons license, unless indicated otherwise in a credit line to the material. If material is not included in the chapter's Creative Commons license and your intended use is not permitted by statutory regulation or exceeds the permitted use, you will need to obtain permission directly from the copyright holder. 